\title{
4-year long progression-free and symptom-free survival of a patient with recurrent glioblastoma multiforme: A case report of the Paleolithic Ketogenic Diet (PKD) used as a stand-alone treatment after failed standard oncotherapy
}

\author{
Csaba Tóth ${ }^{1}$, Andrea Dabóczi ${ }^{1}$, Madhvi Chanrai ${ }^{2}$, Mária Schimmer $^{1}$, Katalin Horváth ${ }^{3}$, \\ Zsófia Clemens ${ }^{1 *}$ \\ ${ }^{1}$ International Center for Medical Nutritional Intervention - Paleomedicina Hungary Ltd., \\ Budapest, Hungary \\ ${ }^{2}$ Independent researcher \\ ${ }^{3}$ County Hospital Zala, Zalaegerszeg, Department of Radiology and Radioisotope Diagnostics \\ *Corresponding author: Zsófia Clemens, $\mathrm{PhD}$
}

Keywords: glioblastoma, brain tumor, paleolithic diet, ketogenic diet, paleolithic ketogenic diet, metabolic therapy, intestinal permeability, cancer treatment

\begin{abstract}
Studies in animal models have suggested that the ketogenic diet may be effective in the treatment of cancer. However, human cohort studies on the ketogenic diet have, thus far, failed to show benefits in cancer survival or in any other hard clinical endpoints of the disease. This paper presents a case report of a patient with glioblastoma multiforme. The patient had initially been treated with standard oncotherapy including surgery, radiotherapy and chemotherapy. Despite standard treatment, the patient experienced a recurrence of the glioblastoma seven months later. Subsequently, the patient refused radiotherapy and chemotherapy and opted to use the paleolithic ketogenic diet (PKD) as a stand-alone therapy. Following the adoption of the PKD, progression of the disease has been completely halted. At the time of writing, the patient has remained in remission for 48 months, is without sideeffects and experiences an excellent quality of life without the use of any drugs.
\end{abstract}

\section{INTRODUCTION}

In recent years there has been a surge of interest in the use of ketogenic diets as a potential treatment for cancer (Klement, 2017). The idea that ketogenic diets may have antitumor effects was initially put forward following the positive findings that emerged from animal studies (Zhou et al., 2007). Clinical studies with the ketogenic diet, have however, repeatedly failed to show benefits in any clinical hard endpoints such as progression-free survival.

The authors of this paper have adopted an evolutionary approach to health and to the treatment of disease. Hence, we have developed and have been using the paleolithic ketogenic diet (PKD) in the treatment of several chronic diseases in more than 5000 patients for the last 
10 years. The PKD is a diet that is based on animal fat and meat and is similar to the diet that was originally proposed by Voegtlin (1975).

In the classic ketogenic diet, the source of the foods is not stipulated; whereas in the PKD the source of the fats and proteins is of the utmost importance. In practical terms this means that the PKD excludes all dairy products, cereal grains, plant oils, nightshades, legumes and dietary supplements; i.e. all foods that were not routinely available before the advent of agriculture 10,000 years ago.

The classic ketogenic diet (and its variants), typically contain unrestricted amounts of dairy products, nuts and plant oils, which are normally excluded in the PKD. In our opinion, this difference accounts for the additional benefits conferred by the PKD as compared to the classic ketogenic diet. We believe that excluding the non-PKD food components results in the normalization of intestinal permeability, which is a critical factor in the mechanism of action of the PKD in cancer (Tóth et al., 2017).

Thus far, we have published several case reports of patients who have been successfully treated with the PKD. These include: type 2 (Tóth and Clemens, 2015a) and type 1 diabetes (Tóth and Clemens, 2014; 2015b); Crohn's disease (Tóth et al, 2016); Gilbert's syndrome (Tóth and Clemens, 2015c); epilepsy (Clemens et al., 2013, 2015); complete reversal of cervical intraepithelial neoplasia (Tóth et al., 2018); halted progression of soft palate cancer (Tóth and Clemens, 2016) and regression of rectal cancer ((Tóth and Clemens, 2017)

Here we present a case report of a patient with glioblastoma multiforme. Initially, the patient had been treated with standard oncotherapy including surgery, radiotherapy and chemotherapy. Despite standard treatment, the patient experienced a recurrence of the glioblastoma seven months later. Subsequently, the patient refused standard oncotherapy and opted to use the PKD as a stand-alone therapy. Since initiating the PKD, progression of the disease has been completely halted. At the time of writing, the patient has remained in remission for 4 years, and that too without the use of any drugs. Furthermore, besides being progression-free, the patient has also been symptom-free.

\section{CASE REPORT}

The medical history of the patient included bladder cancer operated in 2012 . He also had hypertension treated with antihypertensives. The patient presented with severe headache in late January 2016 at the age of 52 years old. A subsequent MRI on the 28th of January 2016 showed a cystic lesion of $44 \times 60 \times 55 \mathrm{~mm}$ in the right parieto-temporo-occipital region with $\mathrm{T} 2$ hyperintensity, and edema resulting in a $10-\mathrm{mm}$ midline shift at the level of the lateral ventricles (Fig. 1.). Histopathology showed polymorph cells, including giant and multinucleated cells as well as necrotic tissue. Immunohistochemistry showed GFAP positivity, Ki67 labeling above $15 \%$ and significant p53 positivity suggesting glioblastoma multiforme. Subtotal surgery was performed the next day. Histopathology indicated glioblastoma multiforme. A follow-up CT scan on 02 Mar 2016 showed a cystic mass of 49 x $29.9 \mathrm{~mm}$ containing another, 33 x 14 mm mass (Fig. 1.). Between March and May 2016 the patient underwent radiochemotherapy along with temozolomide treatment. An MRI in August 2016 showed tumor recurrence (Fig. 1.), whereupon the patient decided to stop standard treatment and contacted us for medical guidance. 


\section{Paleolithic ketogenic diet}

In agreement with the patient, we started the PKD on the 2nd September 2016. The PKD is an animal fat-meat based diet with a fat:protein ratio of approximately 2:1 (in grams). The diet excludes cereal grains, dairy products, nightshades, legumes, plant oils (including coconut oil and olive oil), nuts, refined sugars, artificial sweeteners, food additives and all types of dietary supplements. Red and fatty meats were the predominant foods in the patient's diet, with regular consumption of organ meat from cattle and pork as well. Although the PKD may include some plant foods in certain cases, in this patient's case all plant foods were excluded in order to maximize the effectiveness of the PKD. The patient had two meals a day. He was suggested to eat when hungry, drink when thirsty, and to eat until satiation. The patient has been working full time during his entire follow-up. He was not doing any major exercise or workout.

\section{Follow-up}

The patient was under our close control with frequent personal visits, as well as e-mail and phone communication.

\section{Laboratory workup and urinary ketones}

The patient was followed-up with regular laboratory workups and brain MRI. The patient occasionally checked urinary ketones for his own feedback but did not keep track of these data.

monitoring of urinary ketones

\begin{tabular}{lcccccccc}
\hline & Oct & Feb & Aug & Feb & Aug & Jan & \multirow{2}{*}{ Reference } & Unit \\
& 2016 & 2017 & 2017 & 2018 & 2018 & 2019 & & \\
\hline Glucose & 6.6 & 4.6 & 5.4 & 4.1 & 5 & 4.9 & $3.4-6.1$ & $\mathrm{mmol} / \mathrm{L}$ \\
Cholesterol & 4.6 & 7.6 & 7 & 6.9 & 6.5 & 5.9 & $3.5-6.5$ & $\mathrm{mmol} / \mathrm{L}$ \\
Triglyceride & 0.76 & 1.51 & 0.94 & 0.78 & 0.7 & 0.8 & $0.55-1.85$ & $\mathrm{mmol} / \mathrm{L}$ \\
HDL chol. & 1.63 & 1.79 & 2.08 & - & - & - & $0.9-1.7$ & $\mathrm{mmol} / \mathrm{L}$ \\
LDL chol. & 2.82 & 5.51 & 4.73 & - & - & - & $<3.35$ & $\mathrm{mmol} / \mathrm{L}$ \\
Uric acid & - & - & 254 & 430 & 393 & - & $180-440$ & $\mathrm{umol} / \mathrm{L}$ \\
TSH & - & - & - & 3.97 & 3.64 & - & $0.4-4.5$ & $\mathrm{mIU} / \mathrm{L}$ \\
\hline
\end{tabular}

\section{Table 1.}

Laboratory workup: metabolic parameters. The value that can be regarded as a positive outlier is indicated in red. 


\begin{tabular}{lcccccccc}
\hline & Oct & Feb & Aug & Feb & Aug & Jan & \multirow{2}{*}{ Reference } & Unit \\
& 2016 & 2017 & 2017 & 2018 & 2018 & 2019 & & \\
\hline Sodium & 139 & 140 & 139 & 144 & 139 & 140 & $133-145$ & $\mathrm{mmol} / \mathrm{l}$ \\
Potassium & 3.8 & 4.9 & 5.7 & 3.6 & 4.3 & 4,1 & $3.5-5.5$ & $\mathrm{mmol} / \mathrm{l}$ \\
Chloride & 101 & 98 & 98 & 100 & 99 & 102 & $97-110$ & $\mathrm{mmol} / \mathrm{l}$ \\
Calcium & 2.33 & 2.3 & - & 2.36 & 2.47 & 2.39 & $2-2.6$ & $\mathrm{mmol} / \mathrm{l}$ \\
Iron & - & - & 12.8 & 14.8 & 13.2 & 16.9 & $14-30$ & $\mu \mathrm{mol} / \mathrm{l}$ \\
Magnesium & - & - & 0.9 & 0.99 & 1.02 & 0.84 & $0.78-1.03$ & $\mathrm{mmol} / \mathrm{l}$ \\
Folic acid & - & - & 36.8 & 20.7 & 14.2 & 37.4 & $2.4-45.4$ & $\mathrm{nmol} / \mathrm{l}$ \\
Vit. B12 & - & - & 403 & $>738$ & 505 & 349 & $142-725$ & $\mathrm{pmol} / \mathrm{l}$ \\
Vit. D & - & - & 84.2 & 50.4 & 62.7 & 54.5 & $>75$ & $\mathrm{nmol} / \mathrm{l}$ \\
\hline
\end{tabular}

\section{Table 2}

Laboratory workup: minerals, ions and vitamins. Values that can be regarded as negative outliers are indicated in blue.

\begin{tabular}{lcccccccccc}
\hline & Oct & Feb & Aug & Jan & Feb & Jun & Aug & \multirow{2}{*}{ Jan } & Reference & Unit \\
& 2016 & 2017 & 2017 & 2018 & 2018 & 2018 & 2018 & 2019 & & \\
\hline ESR & 13 & 13 & 13 & 13 & 20 & 18 & 44 & 12 & $<15$ & $\mathrm{~mm} / \mathrm{h}$ \\
CRP & - & - & 0.4 & - & 5.2 & - & & 0.1 & $0-5$ & $\mathrm{mg} / \mathrm{l}$ \\
Fibrinogen & - & - & 4.25 & - & 1.76 & - & 3.41 & 2.05 & $2-4$ & $\mathrm{~g} / \mathrm{l}$ \\
TNF-alpha & - & - & 5.9 & - & 1.6 & 6.09 & 6.85 & - & $1-12,4$ & $\mathrm{pg} / \mathrm{ml}$ \\
IL-6 & - & - & - & - & 3 & $<2$ & 4.8 & - & $0-3,4$ & $\mathrm{pg} / \mathrm{ml}$ \\
\hline
\end{tabular}

\section{Table 3.}

Laboratory workup: inflammatory markers. Values that can be regarded as positive outliers are indicated in red.

Glucose levels were low except for the first measurement shortly after starting the diet. Cholesterol, HDL and LDL cholesterol tended to be slightly elevated. Triglyceride and uric acid were in the normal range. Mineral, ion and vitamin levels were also in the normal range except for the iron being slightly low on two measurements and vitamin D being low upon the last measurement (Table 2.). Inflammatory markers were generally low except for the ESR being elevated on three measurements (Table 3.). Blood work was used to give feedback to the patient on how to fine-tune the diet.

\section{Adherence level}

The patient showed a generally high level of adherence throughout the entire follow-up. This was ascertained by blood work and feedback from the patient. Although the patient did not deviate from the major rules of the PKD he tended to overeat periodically. This may explain the TSH being closer to the upper limit of the normal range, which in our experience indicates relative overeating (Table 1.). The patient also reported having consumed coffee from time to time despite recommendations against drinking coffee. This was reflected in the slightly 
decreased iron levels; coffee consumption has a known effect of lowering iron (Morck et al., 1983).

\section{MRI scans}

During the follow-up of 48 months, nine consecutive MRI scans were performed 3-6 months apart. Each of them showed stable sizes of the tumor and the associated cyst (Figure 1.) except for the last three MRI which indicated a small but gradual decrease in the size of the cyst.

\section{General condition}

Upon diet initiation the patient was mildly overweight (82 kg; $179 \mathrm{~cm}$; BMI: 25.6). During the first six months of the diet he was continuously losing weight. In six months, he lost $10 \mathrm{~kg}$ (BMI: 22.5). Thereafter his weight fluctuated between 72 and $82 \mathrm{~kg}$. The patient was free of symptoms attributable to the brain tumor during the entire follow-up. The patient did not experience epileptic seizures, nor any other neurological symptoms. The patient's blood pressure normalized within one week of starting the diet. His antihypertensive medication was therefore stopped, and his blood pressure has remained normal without medication. The patient retained his physical strength and full work capacity during the entire follow-up. No side-effects of the diet were seen during the 4-year follow-up.

\section{Intestinal permeability test (PEG400 challenge test)}

Intestinal permeability was assessed using a polyethylene glycol (PEG 400) challenge test based on the method of Chadwick et al (1977). PEG 400 contains a mixture of inert watersoluble molecules of at least 11 different sizes. PEG 400 is also nontoxic, not degraded by intestinal bacteria, not metabolized by tissues, and rapidly excreted in urine. After a 3.0-gram oral dose of PEG, the subject makes a six-hour urine collection. Components were separated and quantified by high-performance liquid chromatography (HPLC). The percentage of each fraction of PEG excreted over 6 hours is calculated.

The PEG400 challenge test that was performed in January 2018 (at 17 months on the diet) showed normal intestinal permeability for each of the molecular sizes (Figure 2). This timing corresponded to a time period of not drinking coffee.

\section{Patient Consent}

Written informed consent was obtained from the patient for publication of this case report.

\section{DISCUSSION}

Glioblastoma is the most aggressive form of brain tumor in adults with a prognosis of a median survival of 15 months after standard therapy (Thakkar et al., 2014). Currently, the standard of care for glioblastoma includes surgical debulking along with concurrent 
chemotherapy and radiotherapy. After diagnosis, our patient was also treated with temozolomide and concomitant radiotherapy, despite which a recurrence occurred after seven months. The patient then stopped using standard oncotherapy and started using the PKD as a stand-alone therapy. On this regime, the patient has been progression-free, symptom-free and medicine-free for 38 months.

We have to emphasize that the PKD that we use in the treatment of cancer patients differs from the classic version of the ketogenic diet that has traditionally been used in epilepsy (Kossoff and Rho, 2009) as well as in clinical trials with cancer patients (for a review, see: Klement et al., 2017). The main difference between the classic ketogenic diet (and its variants) and the PKD is that while the classic ketogenic diet is based on plant oils, dairy products and supplements, the PKD is based on animal meat, fat and organ meats.

Despite the popularity of the ketogenic diet, clinical studies with the classic ketogenic diet repeatedly failed to provide evidence that it significantly improves cancer survival (Klement et al., 2017). For example, the ERGO trial, a prospective trial of the ketogenic diet in recurrent glioblastoma, failed to find a meaningful survival benefit (Rieger et al., 2014) while in another study with the ketogenic diet in glioblastoma (van der Louw et al., 2019) overall survival was only 12.8 months.

Currently, there are only case studies that report on long-term survival benefit in cancer due to the ketogenic diet. One case study about two children with astrocytoma dates back to 1995 (Nebeling et al., 1995). Another study reported stable disease while the diet was sustained for seven months (Zuccoli et al., 2010). A recent study using the ketogenic diet along with drugs and hyperbaric oxygen therapy reported two-year survival in a glioblastoma patient (Elsakka et al., 2018), while another one reported complete therapeutic response in a breast cancer patient (İyikesici et al., 2017).

Previously, we have published three cancer case reports, where the PKD resulted in regression or stable disease. In a patient with recurrent cervical intraepithelial neoplasia, the PKD resulted in complete reversal (Tóth et al., 2018). In another patient with an aggressive soft palate cancer, the PKD resulted in progression-free status (Tóth and Clemens, 2016). The two patients are still progression-free at 49 and 59 months after diet onset. In the third patient with rectal cancer, the PKD resulted in a gradual regression while the PKD was highly adhered to (Tóth and Clemens, 2016). We have also reported on other cancer patients with progressionfree survival beyond 2 years (Tóth et al., 2017; Clemens et al., 2019). These successful cases share the PKD as stand-alone therapy administered to the patients (Tóth et al., 2017; Clemens et al., 2019).

In general, ketogenic diets are thought to convey an anticancer effect through targeting the Warburg phenomenon (Seyfried., 2012). Shifting away from a carbohydrate-based metabolism toward a fat-based one has been shown to slow down tumor growth in animal models although it has not been shown to stop cancer growth (Seyfried, 2012).

As we have recently pointed out (Tóth et al., 2017), the general lack of efficacy of the classic ketogenic diet in cancer patients may be due to the fact that the classic ketogenic diet may not convey all the benefits that are associated with the PKD.

Most importantly, a key beneficial mechanism of the PKD over other ketogenic diets is the normalization of intestinal permeability (Tóth et al., 2017). Besides the metabolic 
improvements, it may be this amelioration of intestinal permeability that is crucial to halting cancer progression. We have previously shown that it is the normalization of intestinal permeability rather than the shift to ketosis that is pivotal in the PKD treatment of Crohn's disease and in autoimmune diseases (Tóth et al., 2017). In our experience, certain plant foods prevent complete normalization of intestinal permeability, which is why all plant foods were excluded from this patient's diet.

In another patient with Hodgkin's lymphoma, elevated intestinal permeability was shown to normalize after switching from the classic ketogenic diet to the PKD (Clemens and Tóth, 2019).

Intestinal permeability is a membrane-related phenomenon that prevails at several levels of the organization of the body. Membrane permeability is crucial in defining cell-to-cell communication and in ensuring physiological contact inhibition within tissues. Loss of contact inhibition is known to be associated with a cancerous transformation of tissues (Kojima, 1993). Increased intestinal permeability has been suggested to promote tumorigenesis (Lin et al., 2012) and has been described as being associated with various tumor types (e.g. Soler et al 1999; Melichar, 2007). In 2016 we provided evidence that increased intestinal permeability normalized on the PKD in a Crohn's disease patient in parallel with full recovery from the disease (Tóth et al., 2016). Yet, so far, no dietary or other interventions have resulted in the normalization of intestinal membrane permeability (Oldenwald and Turner, 2013).

Previous dietary intervention trials in cancer patients have not recognized the importance of the intestinal permeability. Also, attempts, until now, have failed to reverse elevated intestinal permeability. For example, a study with the regular paleolithic diet seemed to have no effect on intestinal permeability, nor did it decrease inflammation (Boers et al., 2014).

In cancer patients, a high level of inflammation is regarded as a negative predictor for survival (Strojnik et al., 2014). We put forward that normalizing intestinal permeability is key to controlling inflammation through the application of PKD. Accordingly, we generally see a decrease in the inflammatory markers after a shift toward the PKD (Tóth et al., 2018 and the referenced case studies with the PKD). In our glioblastoma patient, intestinal permeability, as measured by the PEG400 challenge test, also indicated normal intestinal permeability while on the PKD. In our patient, inflammatory markers were generally low, although they fluctuated to some degree during the follow-up. This fluctuation is likely to reflect periods of drinking coffee. The lowest level of the inflammatory markers was seen in the blood work from Jan 2019, a period corresponding to not drinking coffee. Inflammation level being elevated by coffee is indicated by the literature (Zampelas et a., 2004) and is also in accordance with our previous experience.

We are not aware of published studies on intestinal permeability as regards the classical ketogenic diet. Yet, we assume that the classical ketogenic diet does not result in a normalization of the intestinal permeability. We opine that the exclusion of all non-PKD food items (dairy, vegetable oils and supplements which are typically found in the classical ketogenic diet) is a key to normalize intestinal permeability. This notion is supported by a previously published case where in a patient with Hodgkin's lymphoma high intestinal permeability was reversed after shifting from the classical ketogenic diet to the PKD and stopping taking multiple supplements (Clemens and Tóth, 2019). 
Besides the fact that we used the PKD instead of the classic ketogenic diet, another important difference from previous studies is that we used the dietary therapy as a stand-alone treatment. Although it is generally believed that the standard care and dietary therapy can work in synergy (Woolf and Scheck, 2015), we believe that it is the absence of chemotherapy and radiotherapy which contributed to the unexpectedly long progression-free survival in our patient.

Such an assumption agrees with the notion of Seyfried who pointed out that radiotherapy, chemotherapy and the use of steroids may hinder the effect of a metabolic therapy and paradoxically can result in boosting tumor growth through many different paths (Seyfried et al, 2010). Seyfried also raised the possibility that in the future metabolic therapies may become the standard of care in glioblastoma (Seyfried et al., 2019). We suggest that the predominance of chemotherapy and radiotherapy in current oncotherapy may also have prevented clinical trials of the ketogenic diet from major success.

\begin{tabular}{|c|c|c|c|c|c|c|}
\hline & Publication & $\begin{array}{l}\text { Study } \\
\text { type }\end{array}$ & $\begin{array}{l}\text { Patient } \\
\text { number }\end{array}$ & $\begin{array}{l}\text { Diet } \\
\text { type }\end{array}$ & Overall survival & $\begin{array}{c}\text { Time to } \\
\text { progression on } \\
\text { the diet }\end{array}$ \\
\hline \multirow[t]{4}{*}{$\begin{array}{l}\text { Group } \\
\text { studies }\end{array}$} & Champ et al., 2014 & Retrosp. & 6 & $\mathrm{KD}$ & $\begin{array}{c}\text { 4/6 patients alive at } 12 \\
\text { months }\end{array}$ & $\begin{array}{l}5 / 6 \text { patients } \\
\text { progressed at } \\
12 \text { months }\end{array}$ \\
\hline & Rieger et al., 2014 & Prosp. & 17 & $\mathrm{KD}$ & $\begin{array}{l}\text { Median survival } 32 \\
\text { weeks; range: } 6-86+ \\
\text { weeks }\end{array}$ & $\begin{array}{l}\text { All patients } \\
\text { progressed. } \\
\text { Median: } 5 \\
\text { weeks; range: } \\
\text { 3-13 weeks }\end{array}$ \\
\hline & $\begin{array}{l}\text { van der Louw et al., } \\
2019\end{array}$ & Prosp. & 9 & $\mathrm{KD}$ & $\begin{array}{l}\text { Median survival } 12.8 \\
\text { months; range } 9.8-18 \\
\text { months }\end{array}$ & Not reported \\
\hline & $\begin{array}{l}\text { Woodhouse et al., } \\
2019\end{array}$ & Retrosp. & 19 & MAD & 2-year survival $26.7 \%$ & Not reported \\
\hline \multirow[t]{2}{*}{$\begin{array}{l}\text { Case } \\
\text { studies }\end{array}$} & Zuccoli et al., 2010 & $\begin{array}{l}\text { Case } \\
\text { study }\end{array}$ & 1 & $\begin{array}{l}\mathrm{R}- \\
\mathrm{KD}\end{array}$ & Not reported & $\begin{array}{l}10 \text { months } \\
\text { (stopped the } \\
\text { diet at } 7 \\
\text { months) }\end{array}$ \\
\hline & Schwartz et al., 2015 & $\begin{array}{l}\text { Case } \\
\text { study }\end{array}$ & 2 & $\begin{array}{l}\mathrm{R}- \\
\mathrm{KD}\end{array}$ & Not reported & 1 and 3 months \\
\hline
\end{tabular}

Elsakka et al., $2018 \quad$ Case

KMT 24 months (at the time of No progression study writing the paper) at 24 months 


\section{Table 4.}

Dietary intervention studies in glioblastoma multiforme. In the literature, the case with the longest progression-free survival to date is 24 months, as documented by Elsakka et al (2018) (24 months).

KD: ketogenic diet; R-KD: restricted ketogenic diet; MAD: modified Atkins diet; KMT: ketogenic metabolic therapy

We put forward that the failure of previous ketogenic diet trials is not only down to the effect of radiotherapy and chemotherapy that elevate blood glucose levels, but also to the fact that chemotherapy (Keefe et al. 1997) and radiotherapy (Nejdfors et al., 2000) compromise the intestinal barrier and thereby may be counterproductive in cancer treatment.

Medium survival for glioblastoma patients without treatment is three months (Schapira, 2007). As far as we know, our patient is the first glioblastoma patient in the literature receiving a dietary therapy without any other treatment modalities (other than surgery). Currently, with his 48-months progression-free survival and 56 months overall survival (from diagnosis), he has the longest survival of all glioblastoma patients treated with a dietary therapy and published in the literature (Table 4.).

Conflicts of Interest: The authors declare no conflict of interest. 


\section{FIGURE LEGEND}

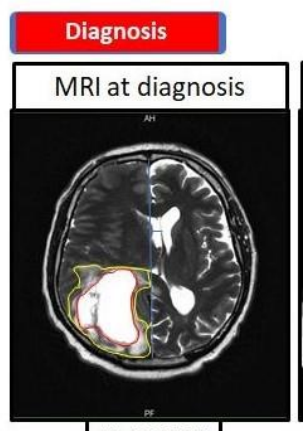

01.28 .2016

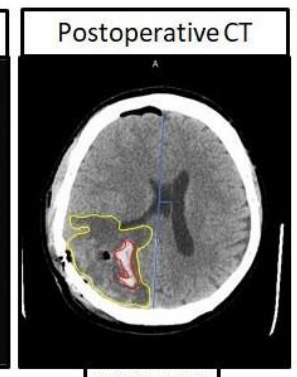

01.30 .2016

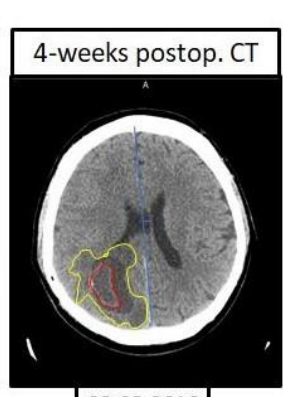

02.03.2016

\section{PKD onset}

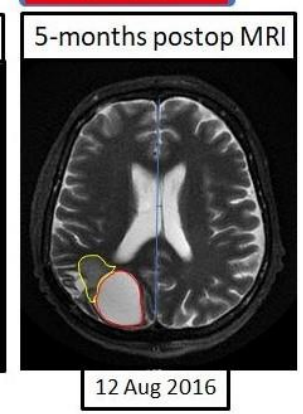

12 Aug 2016

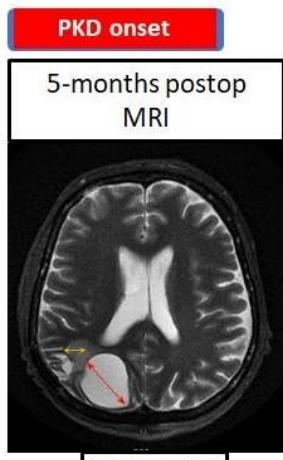

12 Aug 2016

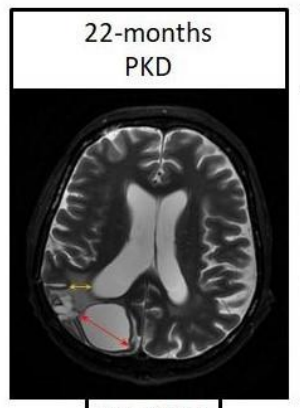

12 Jul 2018

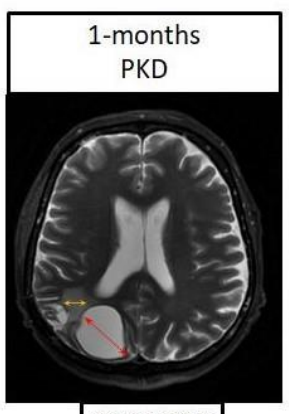

04 Oct 2016

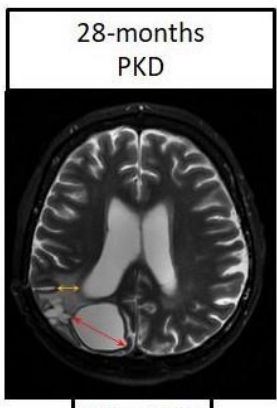

17 Jan 2019
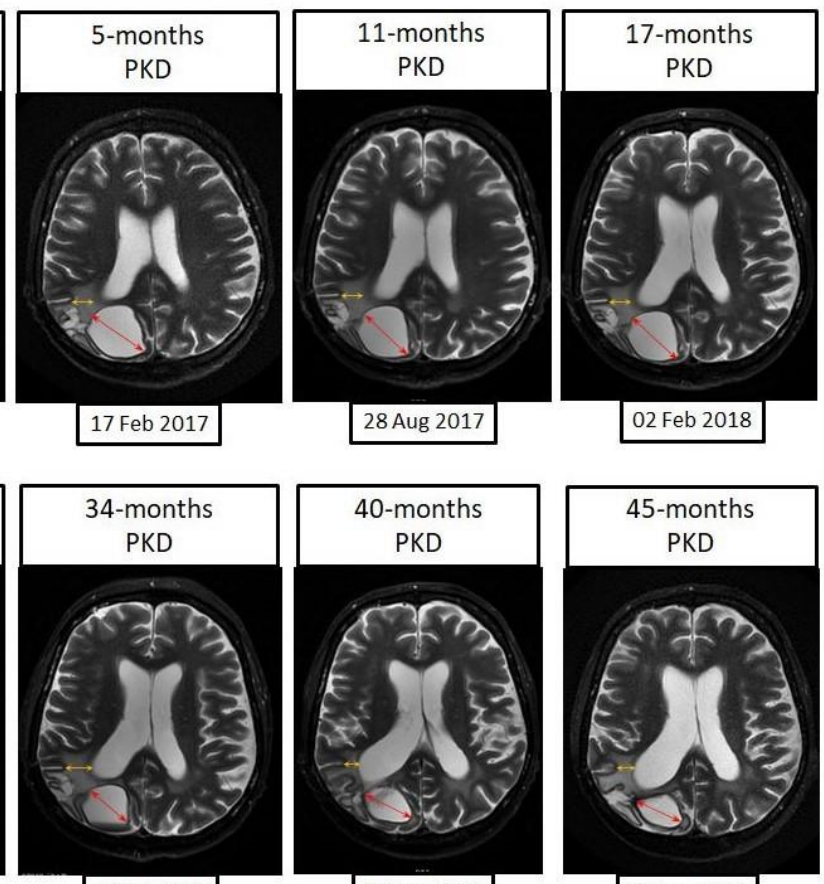

16 Jul 2019

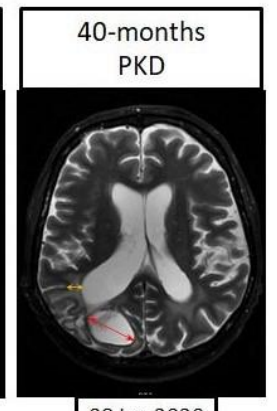

08 Jan 2020

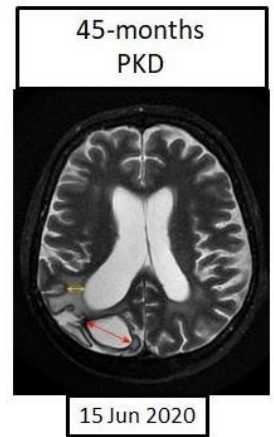

\section{Figure 1.}

MRI and CT scans performed during the course of the disease. Upper row: MRI showing the tumor with the associated cyst upon diagnosis; postoperative CT; 4-weeks postoperative CT; 5-months postoperative MRI.

Manual outline of the cystic tumor is in red. Manual outline of the edema is in yellow. Middle row and bottom row: MRI scan one month before starting the PKD and nine consecutive follow-up MRI scans. Note that there is no change in the size of the tumor and the associated cyst across the first seven MRI scans, but there is a small but gradual decrease in the size of the cyst across the last three MRI scans. Red arrows indicate the cystic tumor while the yellow arrows indicate the edema. 


\section{Figure 2.}

Result of the PEG400 challenge test. The test was done on 21 Jan 2018, at 17 months on the diet. This timing corresponds to a time period of not drinking coffee. Note that intestinal permeability was normal for all the molecular sizes.

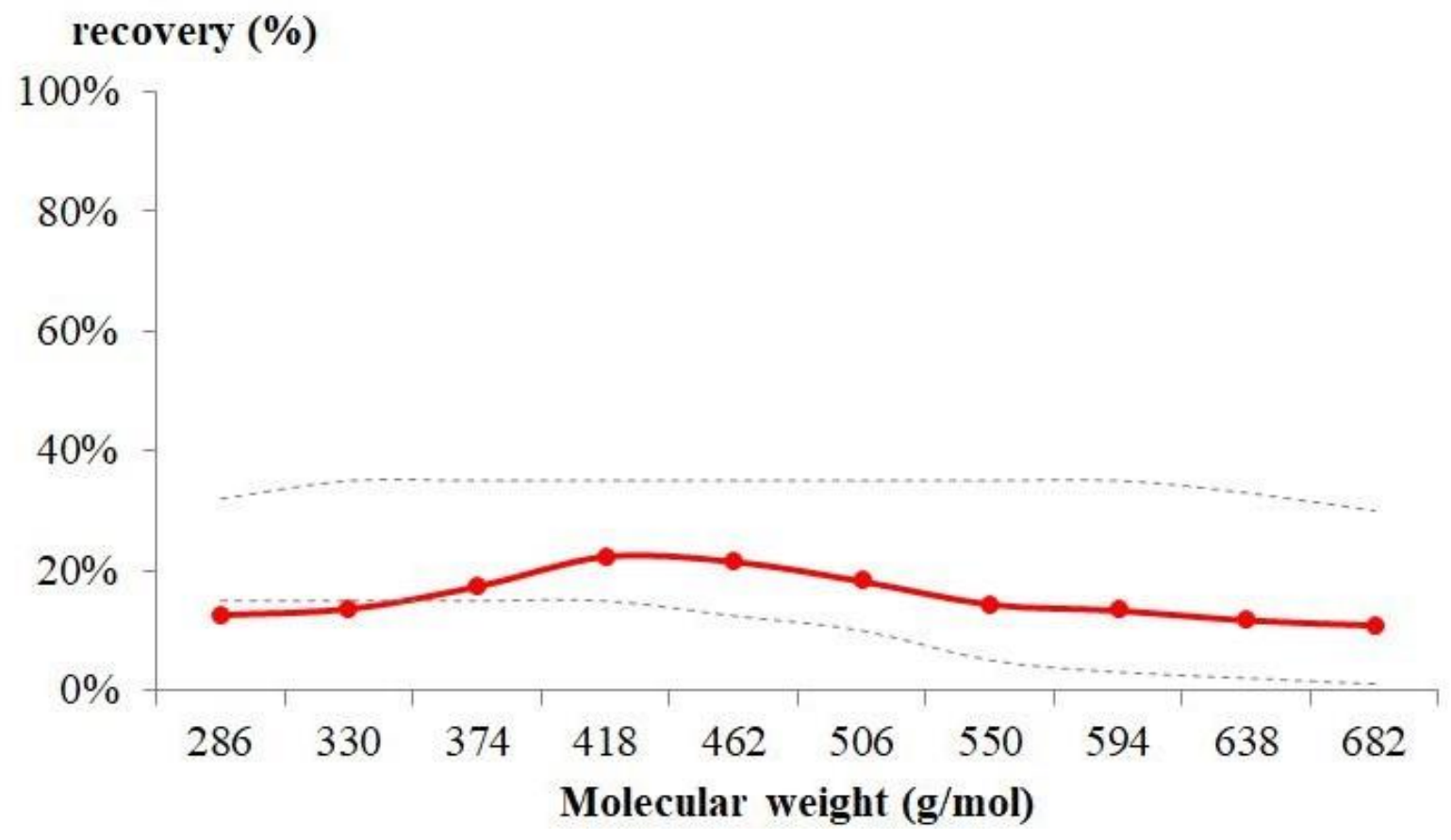

\section{REFERENCES}

Klement RJ. Beneficial effects of ketogenic diets for cancer patients: a realist review with focus on evidence and confirmation. Med Oncol (2017) 34:132. DOI: 10.1007/s12032-0170991-5.

Zhou W, Mukherjee P, Kiebish MA, Markis WT, Mantis JG, Seyfried TN. The calorically restricted ketogenic diet, an effective alternative therapy for malignant brain cancer. Nutr Metab (Lond). 2007 4:5. DOI: 10.1186/1743-7075-4-5.

Voegtlin WL. The stone age diet: based on in-depth studies of human ecology and the diet of man (1975) New York: Vantage Press

Tóth C, Dabóczi A, Chanrai A, Clemens Z. Comment on "Systematic Review: Isocaloric Ketogenic Dietary Regimes for Cancer Patients" by Erickson et al. Journal of Cancer Research and Treatment (2017) 5:86-88. DOI: 10.1007/s12032-017-0930-5

Tóth C, Clemens Z. Successful treatment of a patient with obesity, type 2 diabetes and hypertension with the paleolithic ketogenic diet. Int J Case Rep Images (2015a) 6:161-167. DOI:10.5348/ijcri-201530-CR-10491

Tóth C, Clemens Z. Type 1 diabetes mellitus successfully managed with the paleolithic ketogenic diet. Int J Case Rep Images (2014) 5:699-703. DOI:10.5348/ijcri-2014124-CR10435 
Tóth C, Clemens Z. A child with type 1 diabetes mellitus (T1DM) successfully treated with the Paleolithic ketogenic diet: A 19-month insulin freedom. Int J Case Rep Images (2015b) 6:752-757. DOI:10.5348/ijcri-2015121-CR-10582

Tóth C, Dabóczi A, Howard M, Miller NJ, Clemens Z. Crohn's disease successfully treated with the paleolithic ketogenic diet. Int J Case Rep Images (2016) 7:570-578.

DOI:10.5348/ijcri-2016102-CR-10690

Tóth C, Clemens Z. Gilbert's syndrome successfully treated with the paleolithic ketogenic diet. Am J Med Case Rep (2015c) 3:117-120. DOI: 10.12691/ajmcr-3-4-9

Clemens Z, Kelemen A, Fogarasi A, Tóth C. Childhood absence epilepsy successfully treated with the paleolithic ketogenic diet. Neurol Ther (2013) 2:71-6. DOI: 10.1007/s40120-0130013-2.

Clemens Z, Kelemen A, Tóth C. NREM-sleep associated epileptiform discharges disappeared following a shift toward the paleolithic ketogenic diet in a child with extensive cortical malformation. Am J Med Case Rep (2015) 3:212-215. DOI: 10.12691/ajmcr-3-7-8

Tóth C, Schimmer M, Clemens Z. Complete cessation of recurrent cervical intraepithelial neoplasia (CIN) by the paleolithic ketogenic diet: a case report. Journal of Cancer Research and Treatment (2018) 6:1-5. DOI: 10.12691/jcrt-6-1-1

Tóth C, Clemens Z. Halted progression of soft palate cancer in a patient treated with the paleolithic ketogenic diet alone: A 20-months follow-up. Am J Med Case Rep (2016) 4:288292. DOI: 10.12691/ajmcr-4-8-8

Tóth C, Clemens Z. Treatment of rectal cancer with the paleolithic ketogenic diet: A 24months follow-up. Am J Med Case Rep (2017) 5:205-216. DOI: 10.12691/ajmcr-5-8-3

Morck TA, Lynch SR, Cook JD. Inhibition of food iron absorption by coffee. Am J Clin Nutr (1983) 37:416-20. DOI: 10.1093/ajcn/37.3.416

Chadwick VS, Phillips SF, Hofmann AF. Measurements of intestinal permeability using low molecular weight polyethylene glycols (PEG 400). I. Chemical analysis and biological properties of PEG 400. Gastroenterology (1977) 73:241-6.

Thakkar JP, Dolecek TA, Horbinski C, Ostrom QT, Lightner DD, Barnholtz-Sloan JS, Villano JL. Epidemiologic and molecular prognostic review of glioblastoma. Cancer Epidemiol Biomarkers Prev (2014) 23:1985-96. DOI: 10.1158/1055-9965.EPI-140275.

Kossoff EH, Rho JM. Ketogenic diets: evidence for short- and long-term efficacy. Neurotherapeutics (2009) 6:406-414. DOI:10.1016/j.nurt.2009.01.005

Rieger J, Bähr O, Maurer GD, Hattingen E, Franz K, Brucker D, Walenta S, Kämmerer U, Coy JF, Weller M, Steinbach JP. ERGO: a pilot study of ketogenic diet in recurrent glioblastoma. Int J Oncol (2014) 44:1843-52. DOI: 10.3892/ijo.2014.2382. 
van der Louw EJTM, Olieman JF, van den Bemt PMLA, Bromberg JEC, Oomen-de Hoop E, Neuteboom RF, Catsman-Berrevoets CE, Vincent AJPE. Ketogenic diet treatment as adjuvant to standard treatment of glioblastoma multiforme: a feasibility and safety study. Ther Adv Med Oncol (2019) 11:1758835919853958. DOI: 10.1177/1758835919853958.

Nebeling LC, Miraldi F, Shurin SB, Lerner E. Effects of a ketogenic diet on tumor metabolism and nutritional status in pediatric oncology patients: two case reports. J Am Coll Nutr (1995) 14:202-8. DOI: 10.1080/07315724.1995.10718495

Zuccoli G, Marcello N, Pisanello A, Servadei F, Vaccaro S, Mukherjee P, Seyfried TN. Metabolic management of glioblastoma multiforme using standard therapy together with a restricted ketogenic diet: Case Report. Nutr Metab (Lond) (2010) 7:33. DOI: 10.1186/17437075-7-33. DOI: 10.1186/1743-7075-7-33

Elsakka AMA, Bary MA, Abdelzaher E, Elnaggar M, Kalamian M, Mukherjee P, Seyfried TN. Management of Glioblastoma Multiforme in a Patient Treated With Ketogenic Metabolic Therapy and Modified Standard of Care: A 24-Month Follow-Up. Front Nutr (2018) 5:20. DOI: $10.3389 /$ fnut.2018.00020

İyikesici MS, Slocum AK, Slocum A, Berkarda FB, Kalamian M, Seyfried TN. Efficacy of Metabolically Supported Chemotherapy Combined with Ketogenic Diet, Hyperthermia, and Hyperbaric Oxygen Therapy for Stage IV Triple-Negative Breast Cancer. Cureus (2017) 7;9:e1445. DOI: 10.7759/cureus.1445.

Clemens Z, Dabóczi A, Tóth C. Paleolithic ketogenic diet (PKD) as a stand-alone therapy in cancer: Case studies. Low Carb Denver Conference (2019)

DOI:10.13140/RG.2.2.28600.19208

Seyfried TN. Cancer as a Metabolic Disease: On the Origin, Management, and Prevention of Cancer. Hoboken, New Jersey, Wiley (2012) DOI:10.1002/9781118310311

Clemens Z, Tóth C. Paleolithic ketogenic diet (PKD) in chronic diseases: Clinical and research data. Journal of Evolution and Health (2019) 3:6. DOI: 10.15310/2334-3591.1115.

Kojima K. Molecular aspects in the plasma membrane of tumor cells, Nagoya J Med Sci (1993) 56:1-18.

Lin JE, Snook AE, Li P, Stoecker BA, Kim GW, Magee MS, et al. GUCY2C opposes systemic genotoxic tumorigenesis by regulating AKT-dependent intestinal barrier integrity. PLoS One (2012) 7:e31686. DOI: 10.1371/journal.pone.0031686.

Soler AP, Miller RD, Laughlin KV, Carp NZ, Klurfeld DM, Mullin JM. Increased tight junctional permeability is associated with the development of colon cancer. Carcinogenesis (1999) 20:1425-31. DOI: 10.1093/carcin/20.8.1425

Melichar B, Hyspler R, Dragounová E, Dvorák J, Kalábová H, Tichá A. Gastrointestinal permeability in ovarian cancer and breast cancer patients treated with paclitaxel and platinum. BMC Cancer (2007) 7:155. DOI:10.1186/1471-2407-7-155 
Odenwald MA, Turner JR. Intestinal permeability defects: is it time to treat? Clin Gastroenterol Hepatol (2013)11:1075-83. DOI: 10.1016/j.cgh.2013.07.001.

Boers I, Muskiet FA, Berkelaar E, Schut E, Penders R, Hoenderdos K, et al. Favourable effects of consuming a Palaeolithic-type diet on characteristics of the metabolic syndrome: a randomized controlled pilot-study. Lipids Health Dis (2014) 11:160. DOI: 10.1186/1476511X-13-160.

Zampelas A, Panagiotakos DB, Pitsavos C, Chrysohoou C, Stefanadis C. Associations between coffee consumption and inflammatory markers in healthy persons: the ATTICA study. Am J Clin Nutr. 2004;80:862-7. DOI: 10.1093/ajcn/80.4.862

Strojnik T, Smigoc T, Lah TT. Prognostic value of erythrocyte sedimentation rate and Creactive protein in the blood of patients with glioma. Anticancer Res (2014) 34:339-47.

Woolf EC, Scheck AC. The ketogenic diet for the treatment of malignant glioma. J Lipid Res (2015) 56:5-10. DOI: 10.1194/jlr.R046797

Seyfried TN, Shelton LM, Mukherjee P. Does the existing standard of care increase glioblastoma energy metabolism? Lancet Oncol (2010) 11:811-3. DOI: 10.1016/S14702045(10)70166-2

Seyfried TN, Shelton L, Arismendi-Morillo G, Kalamian M, Elsakka A, Maroon J, Mukherjee P. Provocative Question: Should Ketogenic Metabolic Therapy Become the Standard of Care for Glioblastoma? Neurochem Res (2019) 44:2392-2404. DOI: 10.1007/s11064-019-02795-4

Keefe DM, Cummins AG, Dale BM, Kotasek D, Robb TA, Sage RE. Effect of high-dose chemotherapy on intestinal permeability in humans. Clin Sci (Lond) (1997) 92:385-9. DOI: 10.1042/cs0920385

Schwartz K, Chang HT, Nikolai M, Pernicone J, Rhee S, Olson K, Kurniali PC, Hord NG, Noel M. Treatment of glioma patients with ketogenic diets: report of two cases treated with an IRB-approved energy-restricted ketogenic diet protocol and review of the literature. Cancer Metab (2015)3:3. doi: 10.1186/s40170-015-0129-1.

Nejdfors P, Ekelund M, Weström BR, Willén R, Jeppsson B. Intestinal permeability in humans is increased after radiation therapy. Dis Colon Rectum (2000) 43:1582-1587. DOI: $10.1007 / \mathrm{bf02236743}$

Schapira AH. Neurology and clinical neuroscience. (2007) Philadelphia: Mosby Elsevier. p. 1336. ISBN 9780323070539. 